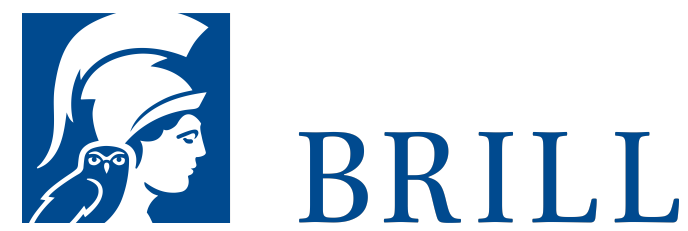

\title{
Menschenrechte, besondere Pflichten und globale Gerechtigkeit
}

Eine Untersuchung zur moralischen Rechtfertigung von Parteilichkeit gegenüber Mitbürgern

Author: Thomas Weitner

In der zeitgenössischen politischen Philosophie wird kontrovers diskutiert, ob sich besondere Pflichten gegenüber Mitbürgern mit einer universalistischen Ethik vereinbaren lassen. Schulden wir unseren Landsleuten mehr als Menschen außerhalb unserer Gesellschaft? Worin bestehen diese besonderen Pflichten? Und wie verhalten sie sich zu allgemeinen Pflichten, die wir gegenüber allen Personen haben? Um diesen Fragen nachzugehen, wird zunächst eine Konzeption der Menschenrechte entwickelt, die sich stark am Werk von Alan Gewirth orientiert, aber auch aktuelle Menschenrechtstheorien kritisch einbezieht. In einem zweiten Teil geht die Untersuchung von der Ebene der Rechte auf die Ebene der Pflichten über. Die zentrale These des Buches besagt, dass es zwei Kategorien besonderer Pflichten gegenüber Mitbürgern gibt: Menschenrechtspflichten und Pflichten der Verteilungsgerechtigkeit. Während Menschenrechtspflichten als bloß zugewiesene und spezifizierte allgemeine Pflichten verstanden werden können, beruhen Gerechtigkeitspflichten auf einem instrumentellen Konzept der Gleichheit, welches erst durch die besondere Verbindung, in der Staatsbürger zueinander stehen, Bedeutung erlangt.

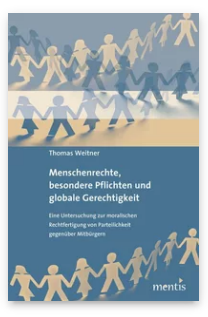

Pages: 291

Seiten

Language:

German

Subjects:

General,

Philosophy

Publisher: Brill | mentis

E-Book (PDF)

Released online:

o1 Jun 2013

ISBN: $978-3^{-}$

89785-976-о

List price

Paperback

Publication date:

o1 Jun 2013

ISBN: 978-3-

$89785^{-827-5}$

List price 
For more information see brill.com

Order information: Order online at brill.com +44330 333 0049 | customerservices@brill.com Submission information: brill.com/authors

Titles published by Brill | Fink, Brill | mentis or Brill | Schöningh: +49(o)715413279216| brill@brocom.de 